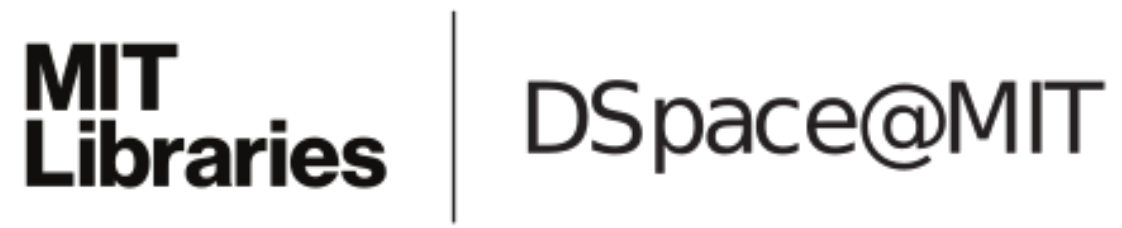

\author{
MIT Open Access Articles
}

\section{GaN-on-Si technology, a new approach for advanced devices in energy and communications}

The MIT Faculty has made this article openly available. Please share how this access benefits you. Your story matters.

Citation: Chung, J. W. et al. "GaN-on-Si Technology, a New Approach for Advanced Devices in Energy and Communications." Proceedings of the European Solid-State Device Research Conference 2010 (ESSDERC). 52-56. (C) Copyright 2010 IEEE

As Published: http://dx.doi.org/10.1109/ESSDERC.2010.5617745

Publisher: Institute of Electrical and Electronics Engineers (IEEE)

Persistent URL: http://hdl.handle.net/1721.1/72603

Version: Final published version: final published article, as it appeared in a journal, conference proceedings, or other formally published context

Terms of Use: Article is made available in accordance with the publisher's policy and may be subject to US copyright law. Please refer to the publisher's site for terms of use. 


\title{
GaN-on-Si Technology, A New Approach for Advanced Devices in Energy and Communications
}

\author{
J. W. Chung, K. Ryu, B. Lu, and Tomás Palacios \\ Department of Electrical Engineering and Computer Science \\ Massachusetts Institute of Technology \\ Cambridge, USA \\ tpalacios@mit.edu
}

\begin{abstract}
The Si substrate of GaN-on-Si wafers offers new opportunities to increase the functionality and performance of nitride-based devices. This paper will review three examples of these new devices/systems. First, GaN-on-Si substrates allow the on-chip heterogeneous integration of $\mathrm{GaN}$ and $\mathrm{Si}$ electronics. Second, the easy removal of the Si substrate through dry or wet etching gives access to the $\mathrm{N}$-face of the $\mathrm{GaN}$ layer, and all the new device structures that this orientation enables. Finally, the use of Si substrates for the growth of GaN high voltage switches makes the cost of these devices competitive with $\mathrm{Si}$ devices, and the total or partial etch of $\mathrm{Si}$ brings a new degree of freedom to increase the breakdown and performance of $\mathrm{GaN}$ transistors.
\end{abstract}

\section{INTRODUCTION}

Nitride semiconductors are quickly transforming our world by enabling new solid-state lighting, highly efficient amplifiers for wireless communications, advanced power electronics with unprecedentedly low losses, and a large array of new high performance devices. Out of the different substrates available for the growth of nitride-based semiconductors (i.e. bulk $\mathrm{GaN}, \mathrm{Si}$, sapphire and $\mathrm{SiC}$ ), the $\mathrm{Si}$ substrate has traditionally been considered a low-cost, lowerperformance option. In this paper we will show that the use of a Si substrate, far from hindering the performance of nitride semiconductors, is a powerful tool that gives unprecedented flexibility for the fabrication of advanced new nitride-based devices.
Three different examples will be discussed. First, the wafer bonding of a GaN-on-Si sample to a $\mathrm{Si}(100)$ wafer has been used to demonstrate the first on-wafer integration of GaN electronics and Si (100) CMOS circuits [1]. This integration allows the combination of the high complexity and flexibility of Si circuits with the vast array of new devices enabled by GaN: transistors, LEDs, energy harvesting devices, and filters. A second example involves the fabrication of $\mathrm{N}$-face $\mathrm{GaN}$ transistors by removing the $\mathrm{Si}$ substrate of a Ga-face-grown sample [2]. These new devices offer new opportunities for improved heat dissipation and high frequency electronics. Finally, the large wafer diameters available for GaN-on-Si samples provide an important competitive advantage for the development of GaN-based high performance power electronics [3]. These devices, with an estimated potential market above $\$ 10$ billion dollar, could be key to energy savings equivalent to $10 \%$ of the global electricity consumption.

\section{ON-WAFER INTEGRATION OF GAN TRANSISTORS AND SI (100) CMOS ELECTRONICS}

The unique properties of AlGaN/GaN High Electron Mobility Transistors (HEMTs) have made them the best option for many RF amplifiers. The unsurpassed high current levels possible in these devices, in combination with their very high breakdown voltage allow almost 10 times higher maximum power density than GaAs amplifiers [4]. In
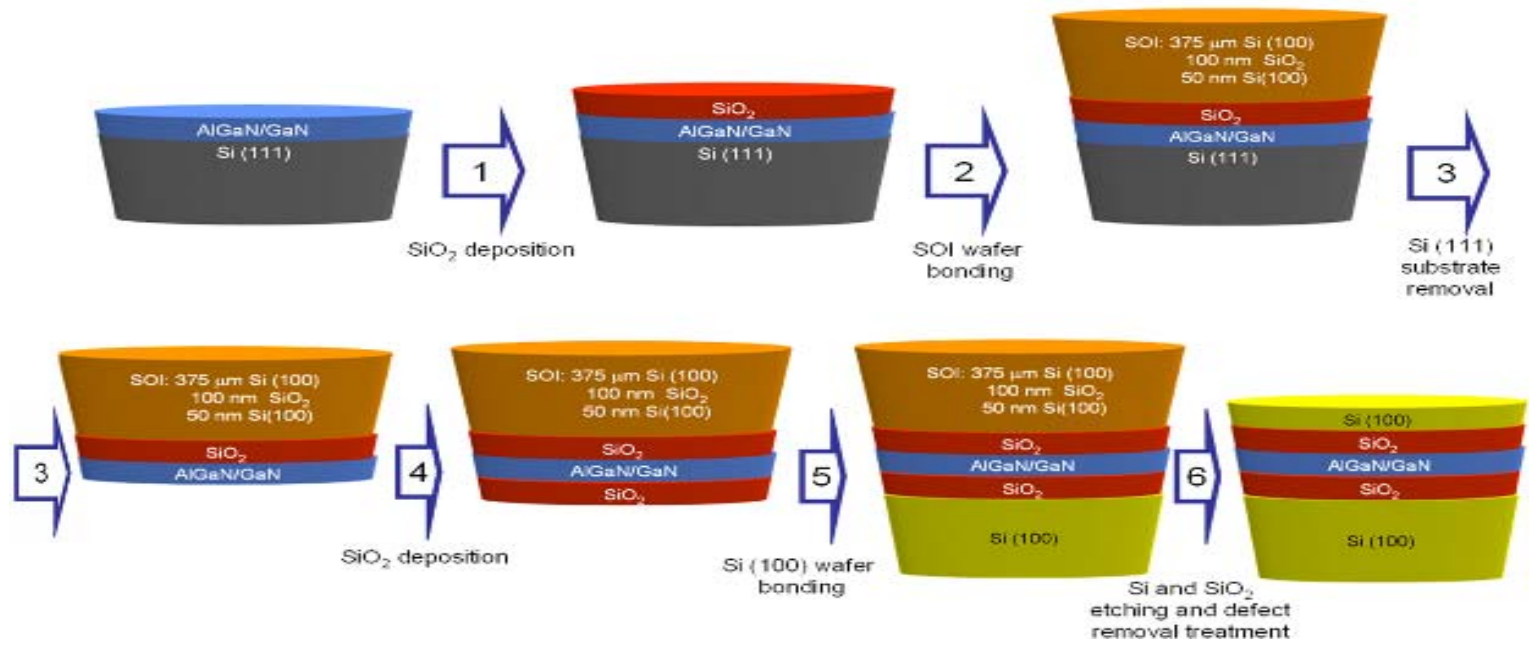

Figure 1. Main steps in the fabrication of a Si/GaN/Si hybrid wafer. 
addition, their high frequency performance enables extremely high power added efficiencies by maximizing the available power gain, and their high output resistance significantly simplifies the design of the matching networks in RF amplifiers. Finally, the recent demonstration of device lifetimes in excess of $10^{6}$ hours at a channel temperature of $175^{\circ} \mathrm{C}$ make this technology one of the most reliable semiconductor technologies.

In spite of the excellent performance demonstrated by nitride transistors, these devices cannot compete with $\mathrm{Si}$ MOSFETs in terms of scalability and level of integration. On the other hand, traditional Si electronics is facing tremendous challenges to continue its scaling and performance improvement. The on-chip heterogeneous integration of $\mathrm{GaN}$ power devices and Si (100) CMOS electronics would enable unprecedented flexibility for advanced circuits, from highly linear power amplifiers, to new power distribution networks in Si microsystems.

The high thermal stability of GaN-based semiconductors makes them ideal for their integration with $\mathrm{Si}$, as the $\mathrm{GaN}$ material can survive the very demanding thermal budget of $\mathrm{Si}$ processing. We have recently demonstrated a technology to integrate, for the first time, these two devices. This technology is based on the fabrication of a hybrid $\mathrm{Si}(001) / \mathrm{GaN} / \mathrm{Si}$ (001) substrate by wafer bonding (Figures 1 and 2). Due to the high thermal stability of GaN, Si CMOS electronics can then be processed in this new substrate without affecting the nitride layers underneath the surface (Figure 3). After the Si devices are fabricated, the $\mathrm{Si}$ material is removed from the regions where nitride devices are needed. Then, the nitride devices (transistors, LEDs, lasers or sensors) are processed and, finally, an interconnection layer forms the final hybrid circuits.

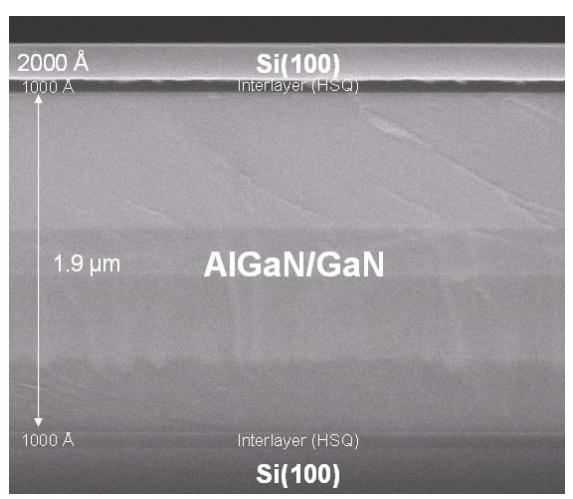

Figure 2. Scanning electron micrograph of the cross-section of a $\mathrm{Si} /$ nitride/Si wafer

Figure 4 shows the scanning electron micrograph of a finished sample where AlGaN/GaN HEMTs were fabricated in very close proximity to $\mathrm{Si}(100)$ pMOSFETs following the process flow outlined in Figure 3. These devices show excellent DC performance and we are currently developing new circuits to take advantage of the flexibility enabled by this integration. Some of these circuits include:
- Integrated $\mathrm{GaN}$ power switches and $\mathrm{Si}$ control electronics

- High power digital-to-analog converters (DACs)

- On-wafer wireless transmitters

- Driver stages for on-wafer optoelectronics

- Power amplifiers coupled to Si linearizer circuits

- High speed (high power) differential amplifiers

- Normally-off power transistors based on the cascaded connection on a Si normally-off transistor and a normally-on GaN HEMT.

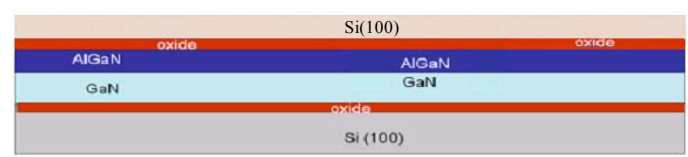

a) Fabrication of Si-GaN-Si hybrid wafer

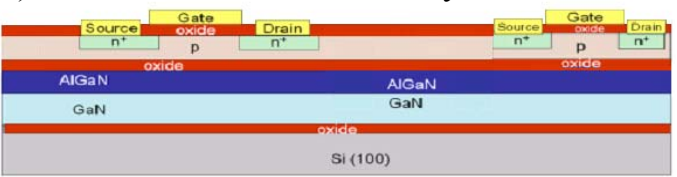

b) Processing of Si CMOS electronics

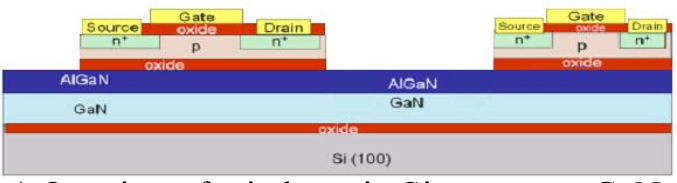

c) Opening of windows in Si to expose GaN

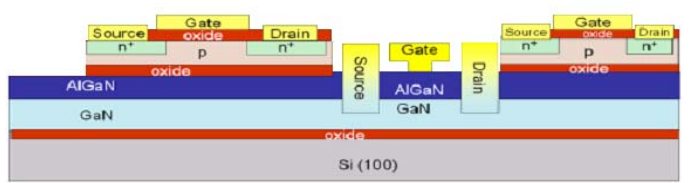

d) Fabrication of GaN devices (e.g. HEMTs)

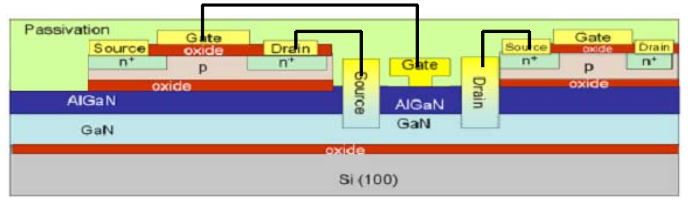

e) Planarization and interconnection layers

Figure 3. Main processing steps for the fabrication of GaN-Si hybrid

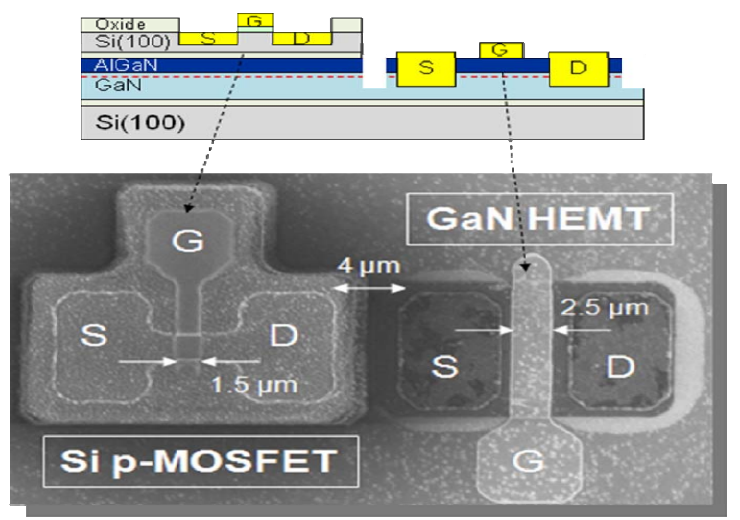

Figure 4. Scanning electron micrograph of the heterogeneous integration of $\mathrm{GaN}$ and $\mathrm{Si}$ electronics. 


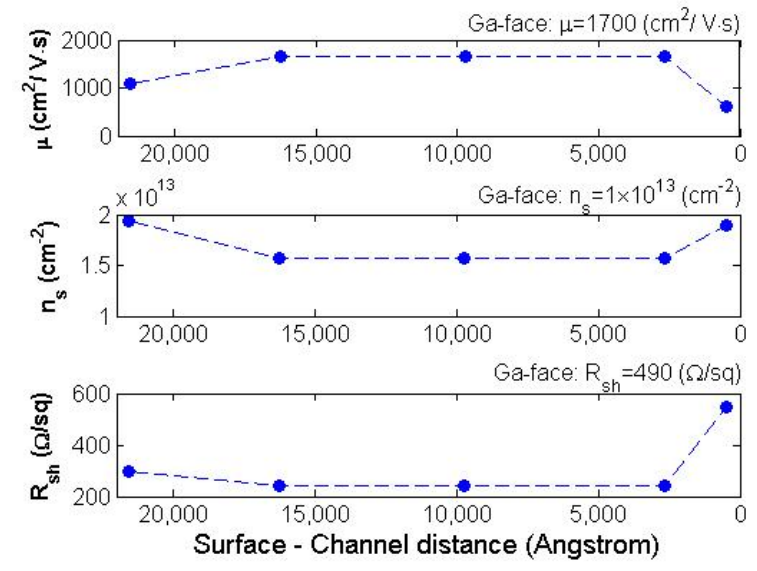

Figure 5. Electron mobility $(\mu), 2 \mathrm{DEG}$ density $\left(\mathrm{n}_{\mathrm{s}}\right)$, and sheet resistance $\left(\mathrm{R}_{\text {sh }}\right)$ of $\mathrm{N}$-face $\mathrm{GaN}$ as a function of the distance between N-face surface and 2DEG channel estimated by room temperature Hall measurement.

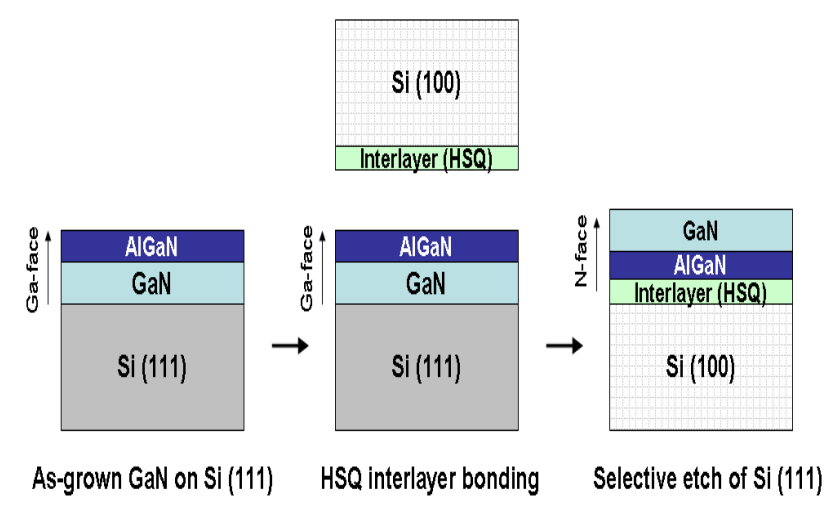

Figure 6. Main processing steps in the fabrication of $\mathrm{N}$-face $\mathrm{GaN}$ on $\mathrm{Si}$ (100) substrate through substrate removal.

- New enhancement-mode power transistors

- Buffer stages for ultra-low-power electronics

\section{N-FACE GAN ELECTRONICS FROM GA-FACE GAN-ON-SI WAFERS}

Although most of the reported GaN devices have been fabricated on nitride structures grown along the c-direction (i.e. Ga-face), N-face GaN/AlGaN transistors have the potential of higher electron confinement and lower contact resistances [5]. However, in spite of this promise, the performance of $\mathrm{N}$-face devices is still much lower than in Gaface devices due to the inferior material quality. Although Nface devices have been grown by molecular beam epitaxy and, recently [6], by metal-organic chemical vapor deposition (MOCVD) [7], the growth of $\mathrm{N}$-face nitrides is much more challenging than the growth of the more stable Ga-face structure. The use of $\mathrm{Si}$ substrates provides a new approach for the fabrication of $\mathrm{N}$-face nitride wafers, not through growth but through the substrate removal of a Ga-face-grown GaN samples, as we will demonstrate in this section.

The Ga-face AlGaN/GaN transistor structures used in this work were grown on $\mathrm{Si}$ (111) substrates by MOCVD at
Nitronex with a structure similar to the one described in Reference [8]. To have access to the N-face of these samples, we have developed the substrate transfer technology shown in Figure 6. First, the Ga-face surface was bonded to a Si (100) carrier wafer by using a hydrogen silsesquioxane (HSQ) interlayer. HSQ is a flowable oxide with excellent thermal stability, which stands the high thermal budget required during the processing of GaN devices. The HSQ film is spincoated on Si (100) to a thickness of about $1000 \AA$ and baked sequentially on hot plates at $150{ }^{\circ} \mathrm{C}$ and $200{ }^{\circ} \mathrm{C}$ for 1 minute each. Then, the HSQ-coated Si (100) substrate is attached to the as-grown $\mathrm{AlGaN} / \mathrm{GaN}$ layer and thermally compressed at $400{ }^{\circ} \mathrm{C}$ for an hour. The elevated temperature hardens the HSQ layer and forms an extremely stable bond between the $\mathrm{GaN}$ wafer and the Si carrier wafer. After the wafer bonding, the original $\mathrm{Si}$ (111) substrate is completely removed by dry etching using an $\mathrm{SF}_{6}$-based dry etch. The GaN buffer is an effective etch-stop layer for the $\mathrm{SF}_{6}$ plasma etch and a smooth $\mathrm{N}$-face GaN surface is obtained at the end of the etch. After the substrate transfer, the $\mathrm{N}$-face $\mathrm{GaN}$ buffer is etched by electron cyclotron resonance reactive ion etching (ECR-RIE) with $\mathrm{Cl}_{2} / \mathrm{BCl}_{3}$ gas mixture until the desired distance between

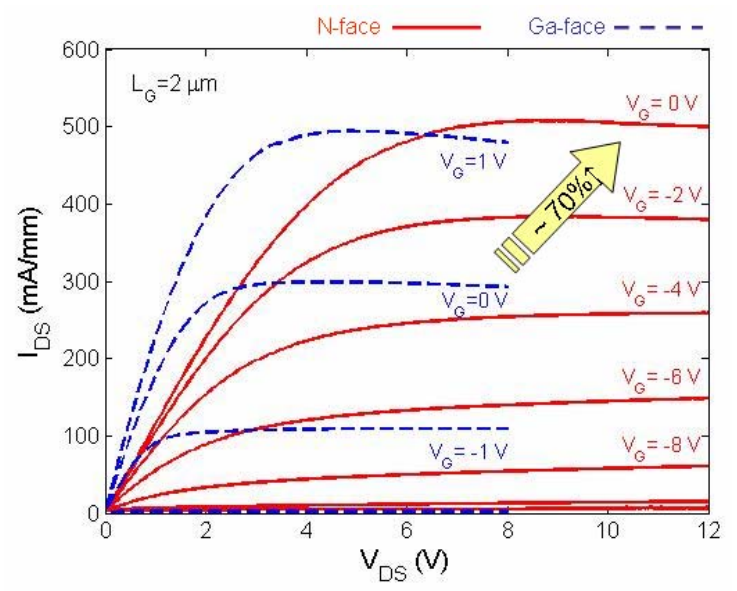

Figure 7. DC current-voltage characteristics of $\mathrm{N}$-face (solid line) and Ga-face (dashed line) HEMTs with a gate length $\left(\mathrm{L}_{\mathrm{G}}\right)$ of $2 \mu \mathrm{m}$. Almost $70 \%$ higher maximum current at $\mathrm{V}_{\mathrm{G}}=0 \mathrm{~V}$ is achieved in N-face HEMTs. Higher on-resistance $\left(\mathrm{R}_{\mathrm{on}}\right)$ in $\mathrm{N}$-face HEMTs is due to non-optimized ohmic contacts.

the $\mathrm{N}$-face $\mathrm{GaN}$ surface and the $\mathrm{AlGaN} / \mathrm{GaN}$ interface is achieved.

The effect of the GaN buffer thickness on the electron transport was evaluated by four-point van der Pauw Hall measurements. The GaN buffer was etched as described in the previous paragraph and the remaining GaN thickness was measured with an interferometer (NanoSpec). The main transport properties are almost constant with buffer thickness $\left(\mu=1670 \mathrm{~cm}^{2} / \mathrm{V} \cdot \mathrm{s}, \mathrm{n}_{\mathrm{s}}=1.6 \times 10^{3} \mathrm{~cm}^{-2}, \mathrm{R}_{\mathrm{sh}}=240 \Omega / \mathrm{sq}\right)$. The sheet resistance is $50 \%$ lower than the sheet resistance measured in the Ga-face of the sample. This important reduction in the sheet resistance is due to an increase in the mobility and electron density during the substrate removal process. The change in the Fermi level pinning when the $\mathrm{N}$-face surface is 
exposed after the substrate removal is believed to be partly responsible for this improvement although other causes are still under investigation.

$\mathrm{N}$-face $\mathrm{GaN} / \mathrm{AlGaN}$ structures fabricated through the substrate removal process described previously have been used in the fabrication of $\mathrm{N}$-face high electron mobility transistors (HEMTs). In this samples, the distance between the N-face surface and the 2DEG was reduced to $1000 \AA$ by a $\mathrm{Cl}_{2}$-based dry etching process. $\mathrm{A} \mathrm{Ti} / \mathrm{Al} / \mathrm{Ni} / \mathrm{Au}$ multilayer was deposited for the ohmic contacts and annealed at $870^{\circ} \mathrm{C}$ for 30 $\mathrm{s}$ in a $\mathrm{N}_{2}$ atmosphere. Then $\mathrm{Cl}_{2} / \mathrm{BCl}_{3}$ plasma was used for the mesa isolation. Finally, a $2 \mu \mathrm{m}$-length gate is defined by photolithography and a $\mathrm{Ni} / \mathrm{Au} / \mathrm{Ni}$ metallization was deposited for the Schottky contact. The drain current versus drain voltage characteristic of the $\mathrm{N}$-face device is shown in Figure 7 and it is compared to a Ga-face HEMT used as a reference. For a gate voltage of $0 \mathrm{~V}$, the maximum current in the $\mathrm{N}$-face device is almost $70 \%$ higher than in the Ga-face device. This difference is mainly due to the higher charge density in the $\mathrm{N}$ face device. The transconductance in this initial $\mathrm{N}$-face deviced is low due to the large gate-to-channel distance.

To improve the performance and yield of this technology, we are currently focused on increasing the wafer diameter and in developing a selective etch technique to reproducibly thin down these $\mathrm{N}$-face wafers and improve, in that way, the device transconductance.

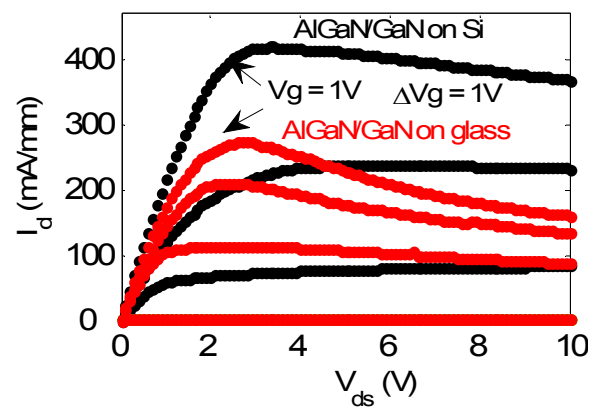

Figure 8. I-V characteristics of an AlGaN/GaN HEMT before and after transferring it to a glass substrate.

\section{GAN-ON-Si POWER ElECTRONICS}

AlGaN/GaN HEMTs grown on Si substrates have also attracted a great interest for power electronics applications. However, despite the low cost of the $\mathrm{Si}$ substrate, the breakdown voltage $\left(\mathrm{V}_{\mathrm{bk}}\right)$ of $\mathrm{AlGaN} / \mathrm{GaN}$ HEMTs grown on $\mathrm{Si}$ (less than $600 \mathrm{~V}$ for $2 \mu \mathrm{m}$ total nitride epilayer) is much lower than that grown on $\mathrm{SiC}(1.9 \mathrm{kV}$ for $2 \mu \mathrm{m}$ total epilayer), which severely reduces device performance. In this section we propose the total or partial removal of the Si substrate to increase the breakdown voltage of GaN power switches grown on Si substrates [3].

For the device demonstration, we used the same standard epitaxial structure described in Section III. In this case, the devices have a gate width of $100 \mu \mathrm{m}$, a $2 \mu \mathrm{m}$ gate length, and varying gate-to-drain distances. To eliminate the vertical breakdown of the AlGaN/GaN HEMTs on $\mathrm{Si}$, we removed

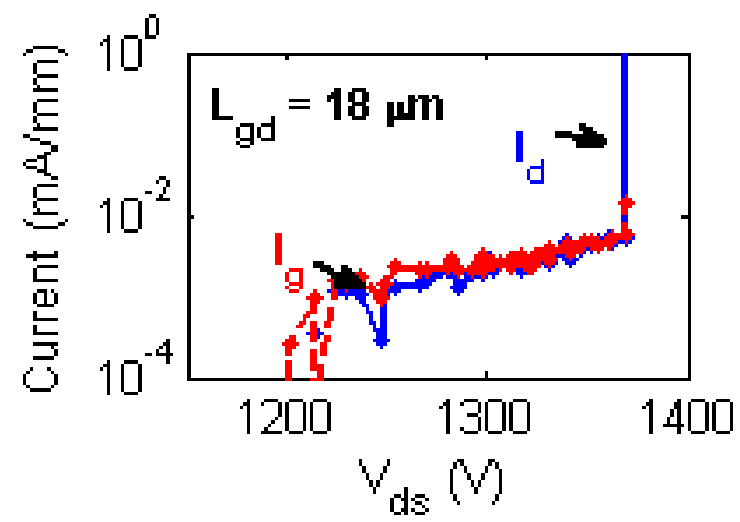

Figure 9. Three terminal breakdown of an $\mathrm{AlGaN} / \mathrm{GaN}$ device on glass with $\mathrm{L}_{\mathrm{gd}}=18 \mu \mathrm{m}$ and $\mathrm{V}_{\mathrm{gs}}=-8 \mathrm{~V}$.

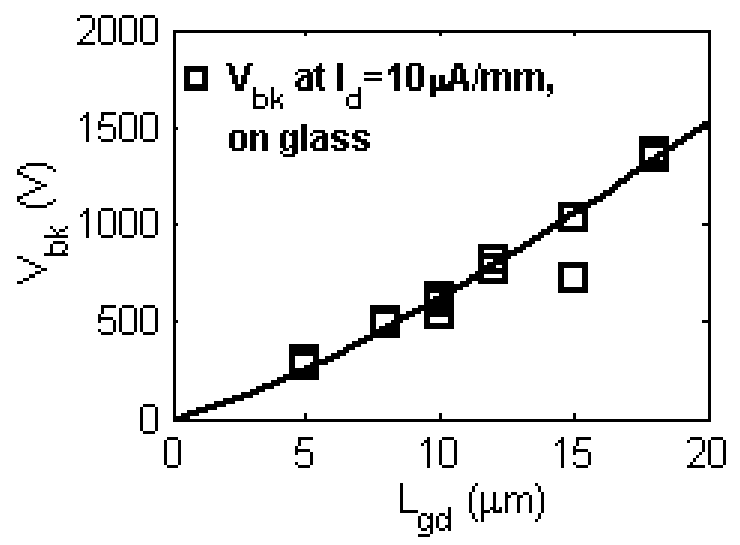

Figure 10. Three terminal breakdown of AlGaN/GaN HEMTs with different $\mathrm{L}_{\mathrm{gd}}$ transferred to a glass substrate.

the Si substrate and transferred the AlGaN/GaN HEMTs to a glass wafer through wafer bonding.

The device maximum current (Figure 8) is lower after bonding to the glass substrate due to increased self-heating, however the breakdown voltage increases significantly. A device with $\mathrm{L}_{\mathrm{gd}}=18 \mu \mathrm{m}$ shows breakdown of $1370 \mathrm{~V}$ and onresistance of $4.3 \mathrm{~m} \Omega \cdot \mathrm{cm}^{2}$ with very low leakage current $(<10$ $\mu \mathrm{A} / \mathrm{mm}$ ) (Figure 9). Three terminal breakdown voltage as a function of gate-to-drain spacing $\left(\mathrm{L}_{\mathrm{gd}}\right)$ is shown in Figure 10 . More than $1450 \mathrm{~V}$ breakdown and an on-resistance of 5.3 $\mathrm{m} \Omega \cdot \mathrm{cm}^{2}$ is achieved on devices with $\mathrm{L}_{\mathrm{gd}}=20 \mu \mathrm{m}$, which is beyond our power supply maximum output voltage. The breakdown voltage of these devices before the $\mathrm{Si}$ removal was below $600 \mathrm{~V}$. These results show the tremendous potential of $\mathrm{GaN}$ heterostructures grown on Si for very high voltage applications, once that the $\mathrm{Si}$ substrate has been removed. It should be noted that the removal of the $\mathrm{Si}$ substrate can be integrated with the packaging of the device, which will reduce cost and increase performance.

\section{CONCLUSIONS}

In summary, the micromachining and processing of the Si substrate in GaN-on-Si wafers is a new tool that device engineers can use to improve the performance and increase 
the flexibility of GaN electronics. This paper has described three different devices where the partial or total removal of the $\mathrm{Si}$ substrate is beneficial: heterogeneous on-chip integration of $\mathrm{GaN}$ and $\mathrm{Si}$ transistors, N-face $\mathrm{GaN}$ devices, and ultra high voltage $\mathrm{GaN}$ power switches. The substrate should, therefore, no longer be considered a secondary part of modern devices GaN-on-Si devices, but an integral part of the device with which achieve higher device performance in applications such as power electronics and high speed communications.

\section{REFERENCES}

[1] J. Chung, J. Lee, E. Piner, and T. Palacios, "Seamless On-Wafer Integration of $\mathrm{Si}(100)$ MOSFETs and GaN HEMTs," IEEE Electron Device Letters, vol. 30, Oct. 2009, pp. 1015-1017.

[2] J. Chung, E. Piner, and T. Palacios, "N-Face GaN/AlGaN HEMTs Fabricated Through Layer Transfer Technology," IEEE Electron Device Letters, vol. 30, 2009, pp. 113-116.

[3] B. Lu and T. Palacios, "High Breakdown ( $>1500 \mathrm{~V}) \mathrm{AlGaN} / \mathrm{GaN} \backslash$ line HEMTs by Substrate Transfer Technology," IEEE Electron Device Letters (in press).
[4] U.K. Mishra, P. Parikh, Y.F. Wu, and others, "AlGaN/GaN HEMTs-an overview of device operation and applications," Proceedings of the IEEE, vol. 90, 2002, pp. 1022-1031.

[5] M.H. Wong, Y. Pei, T. Palacios, L. Shen, A. Chakraborty, L.S. McCarthy, S. Keller, S.P. DenBaars, J.S. Speck, and U.K. Mishra, "Low nonalloyed Ohmic contact resistance to nitride high electron mobility transistors using Nface growth," Applied Physics Letters, vol. 91, 2007, p. 232103.

[6] S. Rajan, A. Chini, M.H. Wong, J.S. Speck, and U.K. Mishra, "N-polar GaN/ AlGaN/ GaN high electron mobility transistors," Journal of Applied Physics, vol. 102, 2007, p. 044501.

[7] S. Keller, N.A. Fichtenbaum, F. Wu, D. Brown, A. Rosales, S.P. DenBaars, J.S. Speck, and U.K. Mishra, "Influence of the substrate misorientation on the properties of N-polar GaN films grown by metal organic chemical vapor deposition," Journal of Applied Physics, vol. 102, 2007, p. 083546 .

[8] J.W. Johnson, E.L. Piner, A. Vescan, R. Therrien, P. Rajagopal, J.C. Roberts, J.D. Brown, S. Singhal, K.J. Linthicum, and R. Therrien, "12 W/mm AlGaN-GaN HFETs on silicon substrates," IEEE Electron Device Letters, vol. 25,2004 , pp. 459-461. 